\title{
Retraction Note: Research on soil structure analysis and VR game experience of Ocean city based on image resolution
}

\author{
Zijian $\mathrm{Li}^{1} \cdot \mathrm{Xiao} \mathrm{Yu}^{2}$
}

Published online: 17 November 2021

(c) Saudi Society for Geosciences 2021

Retraction Note: Arabian Journal of Geosciences (2021) 14: 1653

https://doi.org/10.1007/s12517-021-07829-2

The Editor-in-Chief and the Publisher have retracted this article because the content of this article is nonsensical. The peer review process was not carried out in accordance with the Publisher's peer review policy. Author Zijian Li has not responded to correspondence regarding this retraction. The Publisher has not been able to obtain a current email address for author Xiao Yu.

The original article can be found online at https://doi.org/10.1007/ s12517-021-07829-2

\section{Zijian Li}

jiuwoshujiu81788@163.com

1 School of Fine Arts, Central China Normal University, Wuhan 430079, Hubei, China

2 School of Arts, Hubei University of Education, Wuhan 430205, Hubei, China 